\title{
THE LEFT ATRIUM
}

\section{Book review}

\section{Code 9991 STAT}

\author{
Diagnosing Genius: \\ The Life \& Death of Beethoven \\ François Martin Mai MD \\ McGill-Queen's University Press; 2007 \\ 269 pp \$34.95 ISBN 978-0-7735-3190-1
}

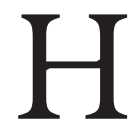

e died at age 57 with a liver that was half its normal size, bluish green in colour and covered with nodules. He had been miserable with reportedly Io episodes of depression and suicidality. He was deaf and his hair showed markedly elevated levels of lead. The women that he pursued considered him "too ugly and half crazy." How could this be the man who created the sublime music that has given me ecstasy throughout my life? The Appassionata, Waldstein Sonata, Piano Concerto No. 4, the Archduke Trio and the sublime Cello Sonata Opus 69, resonate with my right frontal insula, and anterior cingulate cortex and nucleus accumbens.

Indisputably, Beethoven was one of the world's greatest musical geniuses, whose work has inspired cultures around the world for 200 years. But was he a mad genius, bipolar, an alcoholic, and a political and social menace to society? Dr. François Martin Mai presents an answer to these perplexing questions in his beautifully written masterpiece $D i$ agnosing Genius: The Life \& Death of Beethoven. He takes the reader through the social, political, medical and cultural background of the times, which were turbulent to say the least, and sets the o stage for this arts medicine dissertation.

Beethoven, whose mind and body were tortured not only by the times and his environment, also experienced adversity in his childhood, interpersonal difficulties in adulthood and found comfort in wine that was often "fortified with

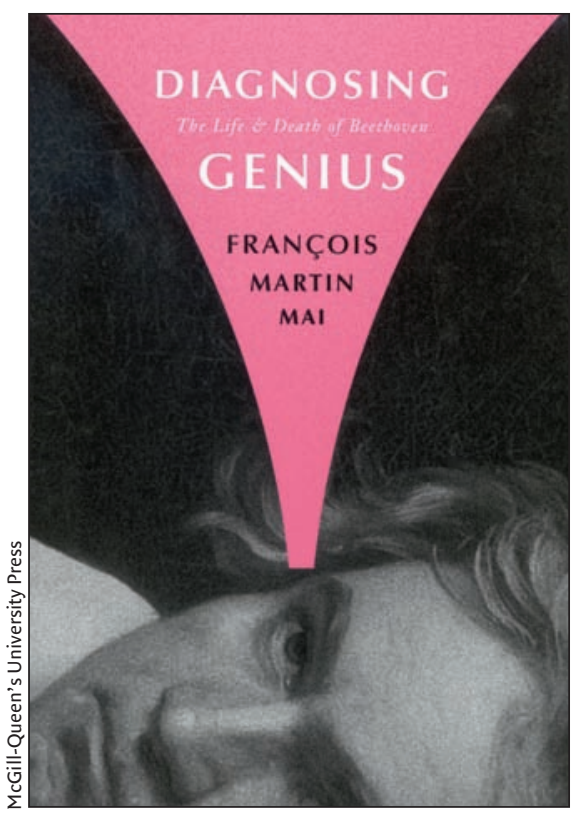

lead oxide." The profound hearing loss that began to afflict him in his early career plunged him into dark moods that brought him to despair and nearly to the point of putting an end to his life. What held him back, according to Mai, was his art: the urge to compose and create complex musical works that have made him immortal. Relative to his elevated artistic excellence, the practice of medicine of that time seems tragically naive.

In Diagnosing Genius, the reader is taken to the beginnings of prescientific medicine, including leeching and "animal magnetism." Beethoven consulted numerous physicians about multiple ailments of the respiratory, gastrointestinal, otologic and neurological systems, as well as his mental state. Without an integrative conceptualization of his allostatic overload, the doctors and patient were left frustrated; discordant in the therapeutic alliance that lacked attunement in their mirror neurons. Beethoven enjoyed his spas, long walks, his beloved wine and, possibly, prostitutes. His romantic urges and fantasies, and angry tantrums toward the myriad injustices of the political and social climate drove him to create symphonies, chamber music and solo repertoire that have inspired composers and performers for generations.

The intersection of illness and creativity, and the apparent contradiction of great human accomplishment in the face of tremendous suffering and despair, is a common thread in the history of art. Mai reviews comprehensively this fascinating literature and its association with various psychiatric diagnoses. He then leads the reader to the plaguing issue of substance abuse amongst creative artists, a curse that has taken the life of many great contributors over the centuries.

Using modern diagnostic categorization, Mai guides the reader through an analysis of Beethoven's health problem. As physicians, we could speculate on how we would diagnose and treat this creative genius today, but one is left with a hollow feeling about the limitations of modern Western medicine during Beethoven's lifetime and, more particularly, its inability to stabilize the interoceptive kindling of the artistic mind.

To derive the greatest satisfaction and pleasure from this wonderful book, it is recommended that the reader get their favourite CDs of Beethoven's I20 hours of creativity, the best sound system that can be had and read while sipping some of the world's greatest vintage wines, of course without lead oxide added.

\section{Freude!}

\section{John Chong MD}

Medical director

Musicians' Clinics of Canada

Toronto, Ont. 